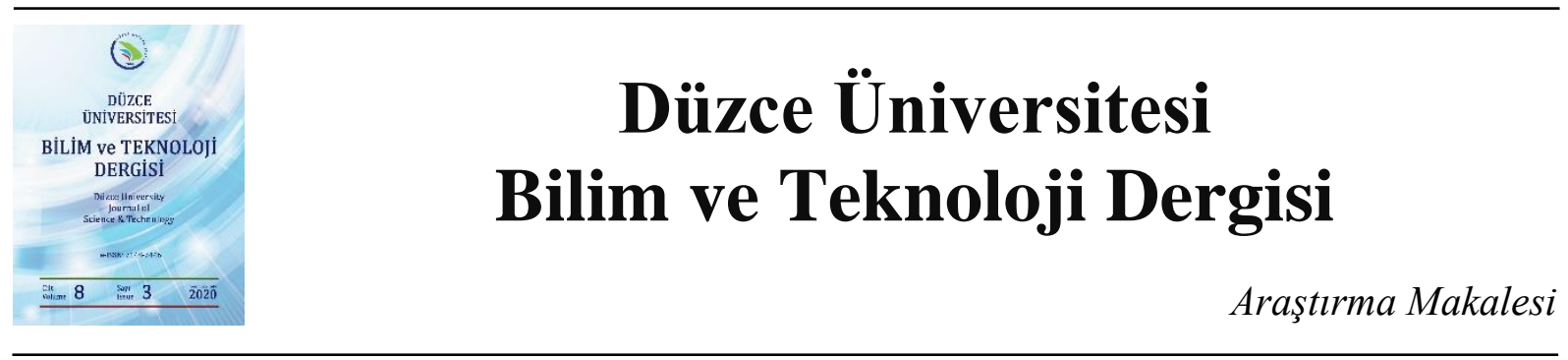

\section{Tek Nokta Enjeksiyonlu Buji ile Ateşlemeli Bir Motorda Motor Devri ve Yükünün Motor Titreşimleri ve Gürültüye Etkisinin Deneysel İncelenmesi}

\author{
Dolga TOPGÜL ${ }^{a^{*}}$, (D) Suat SARIDEMİR ${ }^{\mathrm{b}}$, (D) Çağatay ZAMAN ${ }^{\mathrm{c}}$ \\ ${ }^{a}$ Otomotiv Mühendisliği Bölümü, Teknoloji Fakültesi, Gazi Üniversitesi, Ankara, TÜRKIYE \\ ${ }^{b}$ Imalat ve Makine Mühendisliği Bölümü, Teknoloji Fakültesi, Düzce Üniversitesi, Düzce, TÜRKIYYE \\ ${ }^{c}$ Otomotiv Mühendisliği Anabilim Dall, Fen Bilimleri Enstitüsü, Gazi Üniversitesi, Ankara, TÜRKİYE \\ * Sorumlu yazarin e-posta adresi: topgul@gazi.edu.tr
}

\begin{abstract}
ÖZET
Titreşim ve gürültü gerek günlük hayatta gerekse enerji üretim ve dönüşüm sistemlerinde istenmeyen etkilerdir. $\mathrm{Bu}$ çalışmada, motorun temel işletme parametrelerinden olan motor devri ve yükünün buji ile ateşlemeli bir motorda gürültü ve titreşime etkisi ele alınmıştır. Çalışma deneysel olarak iki aşamada gerçekleştirilmiş̧ir. İlk olarak yüksüz motor şartlarında farklı motor devirlerinde deneyler yapılmıştır. İkinci aşamada sabit motor devrinde (1750 rpm) motor farklı yüklerde çalıştırılmıştır. Bu deney $2500 \mathrm{rpm}$ motor devrinde de tekrarlanmıştır. Yapılan deneylerde elde edilen sonuçlar hem motor devrinin hem de motor yükünün titreşim ve gürültüyü arttırdığg görülmüş̧ür.
\end{abstract}

Anahtar Kelimeler: Buji ile ateşlemeli motor, Motor titreşimleri, Motor gürültüsü, Motor işletme parametreleri

\section{Experimental Investigation of the Effect of Engine Speed and Load on Engine Vibrations and Noise in a Single Point Injection Spark Ignition Engine}

\begin{abstract}
Vibration and noise are undesirable effects in both daily life and energy production and conversion systems. In this study, the effects of engine speed and engine load, which are main operating parameters of the engine, on the noise and vibration were discussed in a spark ignition engine. The study was carried out experimentally in two stages. Firstly, experiments were carried out at different engine speeds under no-load engine conditions. In the second stage, the engine was operated at different loads at constant engine speed (1750 rpm). This experiment was repeated at $2500 \mathrm{rpm}$ engine speed. The results obtained from the experiments have shown that both engine speed and engine load increase vibration and noise.
\end{abstract}

Keywords: Spark ignition engine, Engine vibrations, Engine noise, Engine operating parameters

Geliş: 03/03/2020, Düzeltme: 10/05/2020, Kabul: 04/06/2020 


\section{GIRIS}

18. ve 19. yüzyılda bulunan icatlar ve makineleşme ile ortaya çıkan sanayi devrimi 20. yüzyılda günlük hayatı kolaylaştıran, hızlandıran ve konfor sunan pek çok imkâna kavuşulmasını da sağladı. Bilginin ve bilgiyi uygulamanın daha da önem kazandığı 21. yüzyılda insanoğlu bu gelişmenin ve çevresini saran teknolojinin olumsuz etkilerine daha az maruz kalmak için de çaba sarf etmektedir. $\mathrm{Bu}$ olumsuz etkiler; çevre kirliliği, hava kirliliği, elektromanyetik kirlilik ve gürültü gibi etkilerdir.

İçten yanmalı motorlar özellikle ulaşım alanında günlük hayatı kolaylaştıran ve hız kazandıran temel enerji makineleridir. Ancak içten yanmalı motorlar diğer teknolojik alanlarda olduğu gibi olumsuz etkilere de sahiptir. Titreşim ve gürültü içten yanmalı motorların neden olduğu olumsuz etkilerin arasında gelmektedir.

Çevrimin gerçekleştirilmesi esnasında yanma süreci boyunca meydana gelen ani basınç değişiklikleri ve motor parçalarının doğrusal ya da dairesel hareketindeki ivme değişimleri içten yanmalı motorlarda titreşime neden olan kaynaklardır [1]. Ayrıca motorun ve bağlantı parçalarının hizalama ve gevşeklikleri de bir başka titreşim kaynağıdır [2].

Gürültü de titreşim gibi istenmeyen olumsuz bir etkidir. Motordan kaynaklanan gürültünün üç temel kaynağı vardır. Bunlar; yanma gürültüsü, mekanik gürültü ve emme ile egzoz gürültüsüdür. Yanma gürültüsü, yanma odasındaki hızlı basınç artış artışından kaynaklanır. Mekanik gürültü, motorun dönen veya piston gibi ileri-geri hareket yapan bileşenlerinin neden olduğu gürültüdür [3]. Emme ve egzoz gürültüsü ise; emme ve egzoz sisteminin akustik tasarımına bağlı olarak ortaya çıkan bir gürültü̈dür $[4,5]$.

Benzinli ve dizel motorlarında motor devrinin titreşime olan etkisinin deneysel olarak incelendiği bir çalışmada [6] her iki motor $500 \mathrm{rpm}$ aralıklarla 1000-3500 rpm motor devir aralığında yüksüz olarak çalıştırılmıştır. Titreşim ölçümleri üç eksende ölçüm yapabilen bir ivme ölçer titreşim cihazı ile yapılmıştır. Deneysel çalışma dizel motorundaki titreşimin daha fazla olduğunu göstermiştir. 1000 rpm'de ortalama ivme dikkate alındığında benzinli motora kıyasla dizeldeki titreşimin 42,2 kat daha fazla elde edilmiştir. Araştırmacılar sıkıştırma oranının ve maksimum basıncın farklı olması nedeniyle bu sonucun ortaya çıkabileceğini ifade etmişlerdir.

Sarıdemir ve arkadaşları tarafından yapılan çalışmada [7] bir dizel motorunun titreşim ve gürültüsüne motor devri ve yükünün etkisi incelenmiştir. Deneysel olarak gerçekleştirilen çalışma yüklü ve yüksüz olarak 1500, 2000 ve $2500 \mathrm{rpm}$ motor devirlerinde yapılmıştır. Yanma ile silindir içerisinde oluşan ani basınç artışının yanma odası duvarlarına etkisinin motor titreşimlerine neden olduğunun belirtildiği çalışmada ayrıca titreşimin ses oluşturduğu ve motor titreşim genliği ile gürültünün doğru orantılı olarak değiştiği belirtilmiştir. Silindir içerisindeki yanma basıncının ve motor parçaları arasındaki sürtünmenin motor devri ve yüküne bağlı olarak artmasının etkisiyle motor titreşimleri ve gürültünün arttı̆̆ çalışmanın sonucu olarak elde edilmiştir.

Karabulut ve çalışma arkadaşlarının dört zamanlı tek silindirli bir dizel motorunun dinamik modelini oluşturdukları çalışmada [8] motor bloğunun titreşimleri incelenmiştir. Çalışmada motor bloğunun silindir ekseni doğrultusunda öteleme hareketi ve krank mili ekseni doğrultusunda dönme hareketi yapan iki serbestlik derecesine sahip olduğu dikkate alınmıştır. Motor bloğunun açısal titreşimlerine silindir içerisinde oluşan gaz basıncının daha fazla silindir ekseni doğrultusundaki blok titreşimlerine ise pistonun kütlesinin daha çok etkisi olduğu çalışmanın sonucunda elde edilmiştir.

Karabulut ve Öztürk tarafindan yapılan çalışmada [9] motor bloğunun açısal titreşim genliklerinin artan motor yükü ile arttığı tespit edilmiştir. Esen ve Tacir tarafından yapılan çalışmada [10] ise; titreşimin makinenin dengesiz kütlesinden kaynaklandığı ifade edilmiştir. Seifi ve çalışma arkadaşları tarafindan dizel motoru üzerinde yapılan çalışmada [11] motor gürültüsünün motor hızı, yakıt tipi ve motor yükünden önemli derecede etkilendiği vurgulanmıştır. Satsangi ve Tiwari dizel/n-bütanol 
karışımlarını test ettikleri çalışmalarında [12] artan motor yükünün yanma gürültüsünü arttırdığı ifade edilmiş̧ir. Araştırmacılar motor yükünün artışı ile enjektörden püskürtülen yakıt miktarının artması ve bunun sonucu olarak daha yüksek silindir basınçlarına ulaşılmasının etkili olduğunu belirtmişlerdir.

Bu çalışmada buji ile ateşlemeli bir motorun motor devri ve yüküne bağlı olarak motor titreşimlerinin değişimi deneysel olarak incelenmiştir. Çalışma yüklü ve yüksüz olarak iki aşamada gerçekleştirilmiştir. Yüksüz motor deneylerinde motor titreşimlerine motor devrinin etkisi, yüklü motor deneylerinde ise; sabit motor devrinde motor yükünün titreşime etkisi incelenmiştir.

\section{MATERYAL VE METOT}

Motor titreşimlerinin deneysel olarak belirlenmesi için gerçekleştirilen bu çalışmada testler yüksüz ve yüklü olmak üzere iki farklı durumda yapılmıştır. Motorun yüksüz olarak çalıştırıldığı ilk aşamada değişken olarak motor devri ele alınmıştır. Yüksüz motor deneylerinde motor devri, rölanti devri (890 $\mathrm{rpm}$ ) ile $3250 \mathrm{rpm}$ aralığında değiştirilmiştir. Yüklü motor deneyleri sabit motor devrinde (1750 ve $2500 \mathrm{rpm}$ ) tam yükte ve kısmi yüklerde gerçekleştirilmiş̧ir. Tüm testlerde aynı yakıt (95 oktan kurşunsuz benzin) kullanılmıştır.

Deneysel çalışma Cussons P8653 test standına bağlanan motorda gerçekleştirilmiştir. Deney motoru, dört zamanlı, dört silindirli, su soğutmalı, tek nokta yakıt enjeksiyonlu buji ile ateşlemeli bir motordur. Tablo 1'de deney motorunun teknik özellikleri yer almaktadır.

Tablo 1. Testlerin gerçekleştirildiği motorun özellikleri

\begin{tabular}{ll}
\hline Test Motoru & Ford VSG 413 \\
\hline Silindir Çapı X Kurs & 73,96 X 75,48 mm \\
Toplam Kurs Hacmi & $1297 \mathrm{~cm}^{3}$ \\
Sıkıştırma Oranı & $8,8: 1$ \\
Maksimum Motor Torku & $98 \mathrm{Nm}(2500 \mathrm{rpm})$ \\
Maksimum Motor Gücü & $43 \mathrm{~kW}(5000 \mathrm{rpm})$ \\
\hline
\end{tabular}

Cussons P8653 test standı üzerinde bulunan deney motoru elektrikli dinamometreye (David McClure Ltd.) bağlı olup deneyler esnasında ölçülen çeşitli veriler masaüstü bilgisayara Windows işletim sistemi tabanında çalışan Engine Data Logging programı yardımıyla aktarılmaktadır. Test düzeneği Şekil 1'de yer almaktadır.

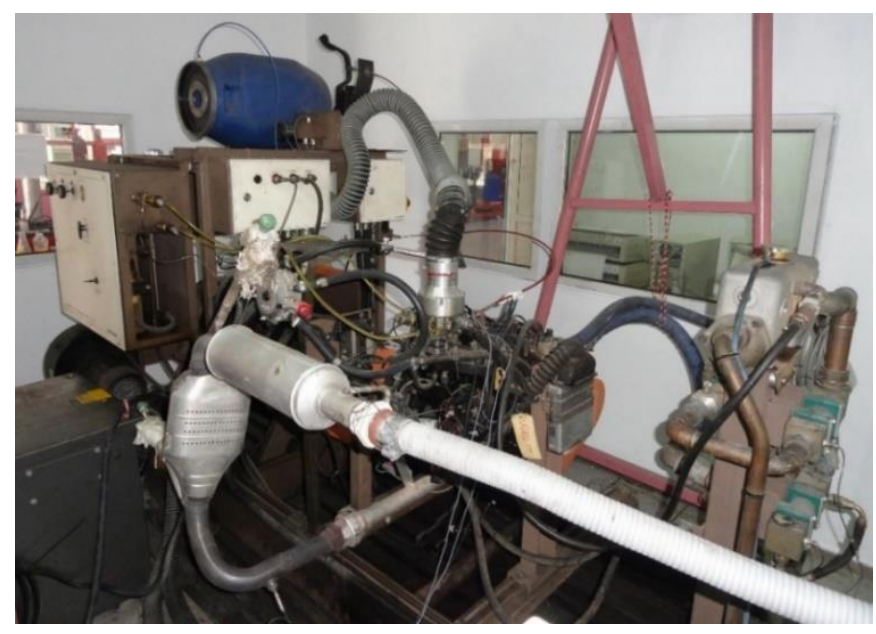

Şekil 1. Cussons P8653 test standl 
Testlerde Brüel \& Kjaer 4527 marka üç eksenli piezoelektrik ivme ölçer motor titreşimlerinin ölçülmesi için Şekil 2. a'da görüldügü motor üzerinde konumlandırılmıştır. Bu cihaz 0,3-10000 Hz frekans aralığına ve $10 \mathrm{mV} / \mathrm{g}$ hassasiyetine sahiptir. Ayrıca Vibrotest 80 model FFT analizi yapabilen veri toplama cihazı (Şekil 2. b) kullanılarak titreşim ölçümleri alınmıştır.

Gürültü ölçümü için ölçüm aralığ 55 dBA RMS $\div 140,1 \mathrm{dBA}$ ve frekans aralığı $30 \mathrm{~Hz} \div 8 \mathrm{kHz}$ olan Svantek 104 model dozimetre (Şekil 2. c) kullanılmıştır. Ölçüm işlemi, ISO 362-1:2007 standardına uygun olarak motor bloğundan $1 \mathrm{~m}$ uzaklıkta yapılmıştır.

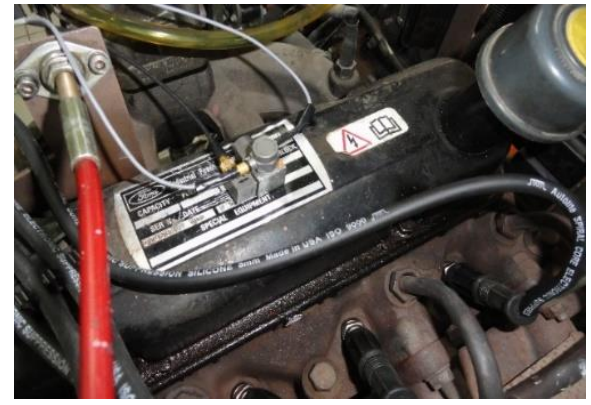

(a)

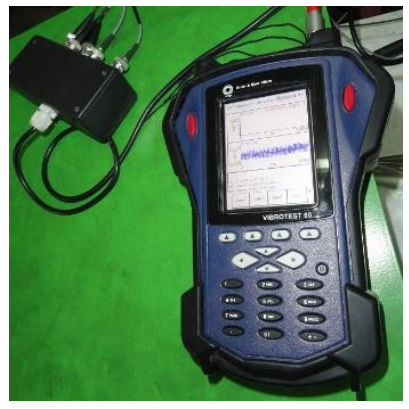

(b)

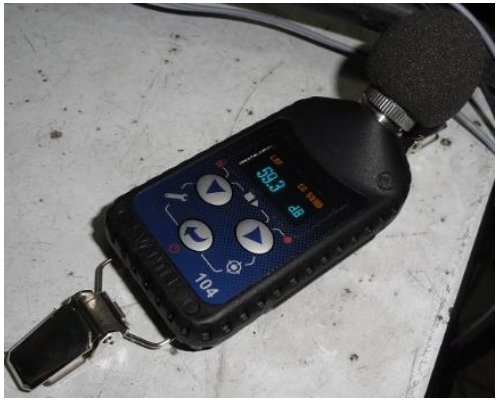

(c)

Şekil 2. (a) Brüel \& Kjaer 4527 model üç eksenli piezoelektrik ivme ölçerin motor üzerindeki konumu (b) Vibrotest 80 model veri toplama cihazı (c) Svantek 104 model dozimetre

İvme ölçer, motor külbütör kapağına yapıştırma ile bağlanmıştır. İvme ölçerin krank ekseni doğrultusu (ch1), yanal (ch2) ve dikey (ch3) eksenler sırasıyla x, y, z ile gösterilmiştir.

Bir dakika boyunca alınan her bir ölçümde $5 \mathrm{kHz}$ e kadar olan titreşim verileri toplanmıştır. Her bir ölçüm için toplam 16384 veri alınmıştır. Ölçümlerin analizi 6400 çözünürlükte Hanning filtreleme yöntemi ile yapılmıştır. Ortalama karekök (RMS) alınarak titreşim sinyallerinin toplam genlik değerleri belirlenmiştir.

\section{BULGULAR}

$1750 \mathrm{rpm}$ ve $2500 \mathrm{rpm}$ motor devirleri için ch3 kanalından alınan verilere göre çizilen frekans ve zaman bölgesi grafikleri Şekil 3'te görülmektedir. Şekil 3'te $2500 \mathrm{rpm}$ motor devrinde 1750 rpm'ye göre daha büyük ivme (titreşim) değerlerinin elde edildiği görülmektedir. Frekans bölgesi grafikleri incelendiğinde $250 \mathrm{~Hz}$ 'in altında ve $500 \mathrm{~Hz}-2500 \mathrm{~Hz}$ aralığında (z) ekseninde en büyük ivme değerinin olduğu görülmektedir. Titreşimin zamana bağlı olarak değişimini zaman bölgesi ifade eder. Test motoru dört zamanlı olup krank milinin iki turunda bir iş meydana gelmekte ve silindire bu sürede bir kere hava/yakıt karışımı alınmaktadır. Motorun bir saniyedeki dönüş sayısı dikkate alındığında 1 saniyede $1750 \mathrm{rpm}$ için yaklaşı 15 çevrim, $2500 \mathrm{rpm}$ için ise 21 çevrim gerçekleştiği görülür. Gerçekleşen her bir çevrimde meydana gelen yanma sonucunda zaman bölgesi grafiklerinde görüldüğü gibi her iki devirde de bu değerlerle uyumlu maksimum titreşim değerleri elde edilmiştir. 


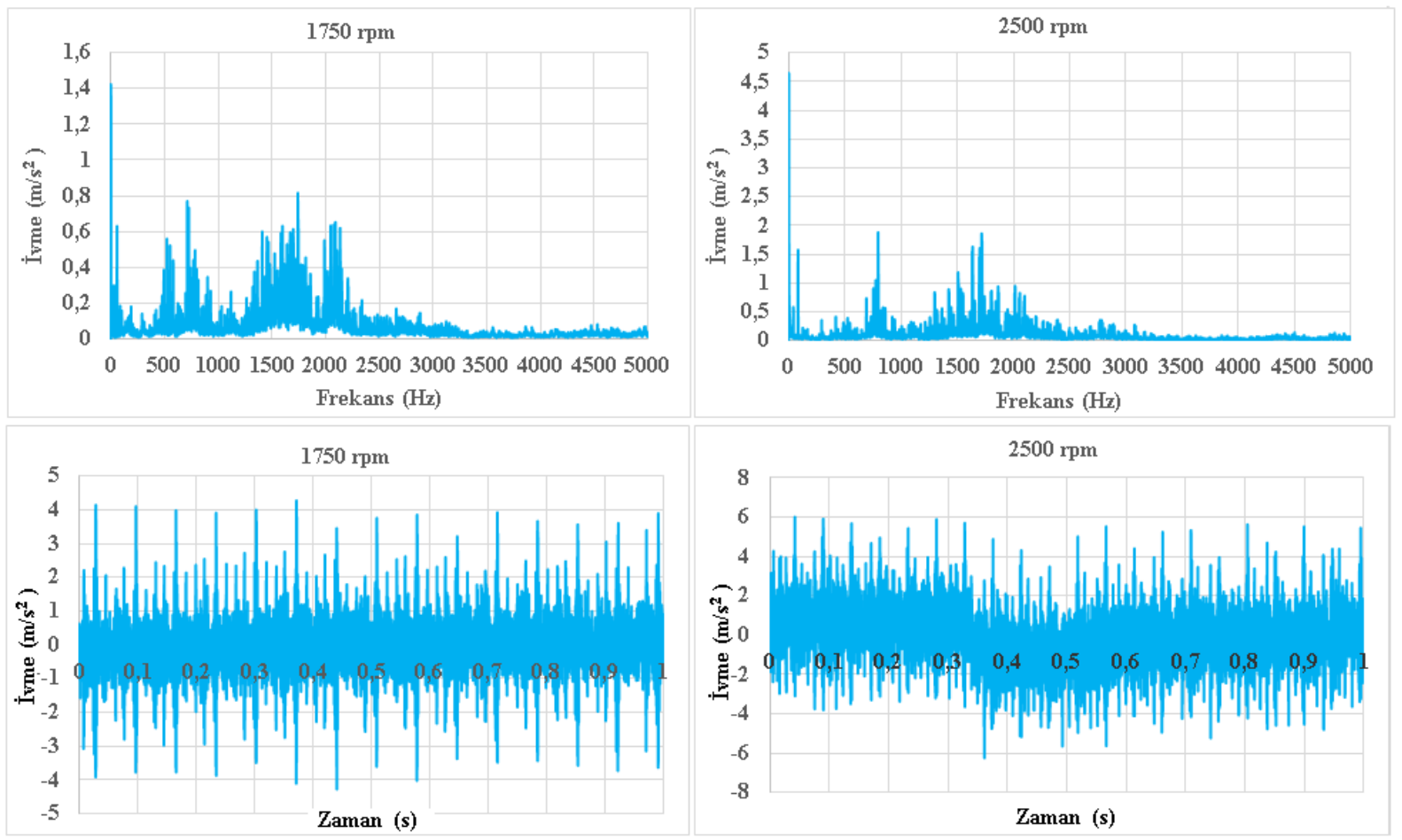

Şekil 3. 1750 ve 2500 rpm motor devirlerindeki frekans ve zaman bölgesi grafikleri

Her bir testte elde edilen titreşimleri karşılaştırılabilmek için ivme ölçerin her bir kanalından alınan ivme değerleri kullanılarak ortalama karekök değerleri (a $\left.a_{\text {RMS }}\right)$ Eşitlik l'de verilen denklem ile hesaplanmıştır [13-16].

$a_{\mathrm{RMS}}=\sqrt{\frac{1}{\mathrm{n}} \sum_{\mathrm{k}=1}^{\mathrm{n}} \mathrm{a}_{\mathrm{k}}^{2}}$

Şekil 4'te çeşitli motor devirlerinde ch1, ch2 ve ch3 kanallarından alınan (x, y ve z eksenleri) ve Eşitlik 1 ile hesaplanan titreşim verilerinin ortalama karekökünün (aRMS) değişimi görülmektedir.

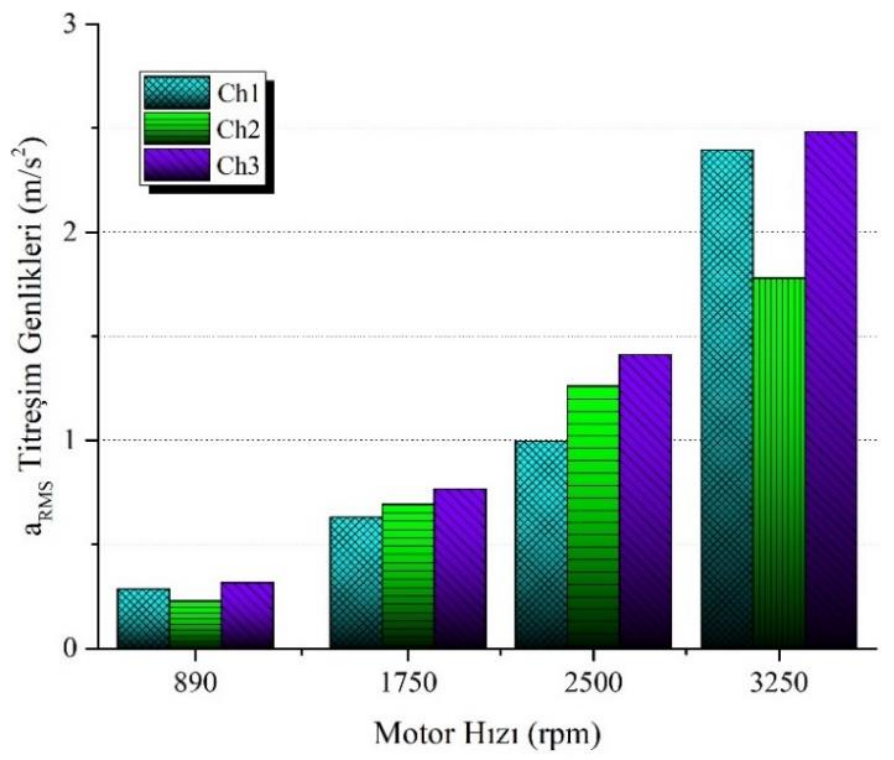

Şekil 4. Her bir kanaldaki titreşim genliklerinin değişimi 
Krank ekseni doğrultusundaki x yönündeki (ch1 kanal1), yanal y yönündeki (ch2 kanalı) ve dikey-z yönündeki (ch3 kanalı) titreşim genlikleri motor devrine bağlı olarak artış göstermiştir. Krank ekseni ve yanal doğrultudaki titreşim genlikleri birim zamanda yapılan çevrim sayısından etkilense de deneylerin yapıldığ tüm motor devirlerinde en fazla titreşimin dikey-z yönünde (ch3 kanalı) olduğu Şekil 4'te görülmektedir. Bu sonuç motorun diğer eksenlere kıyasla dikey yönde daha fazla salınım yaptığını göstermektedir. Silindir içerisinde pistonlar düşey doğrultuda çalıştığından bu yönde daha fazla ivme genlik değerleri elde edilmiştir. Bu sonuç atalet kuvvetlerinin dikey doğrultuda diğer eksenlere kıyasla daha büyük olmasından kaynaklanmaktadır. Benzer titreşim sonuçlarının elde edildiği çalışmalarda $[3,12]$ araştırmacılar titreşimin pistonun hareket doğrultusundaki eksende daha yüksek olduğunu tespit etmişlerdir.

Motorun yüksüz olarak çalıştırıldığı testlerde motor devrine bağlı olarak toplam ortalama titreşimin değişimi Şekil 5 'te yer almaktadır. Grafikte yer alan toplam ortalama titreşim değerleri ( $\left.a_{\text {toplam }}\right)$ her bir eksendeki (x, y ve z) a RMS ivme değerleri ve Eşitlik 2 [13-16] kullanılarak elde edilmiştir.

$a_{\text {toplam }}=\sqrt{a_{\text {RMS(x) }}^{2}+a_{\text {RMS }(y)}^{2}+a_{\text {RMS(z) }}^{2}}$

Şekil 5’te görüldügüü gibi motor devir artışına bağlı olarak motor titreşimleri de artış göstermektedir. $\mathrm{Bu}$ artışta birim zamanda gerçekleşen çevrim sayısının motor devrine bağlı olarak artması etkili olmaktadır. Ayrıca yüksüz şartlarda gerçekleştirilen testlerde motor hızının arttırılması için gaz kelebek açıklığının da bir miktar arttırılması gerekmektedir. Gaz kelebek açıklığının artmasına bağlı olarak silindir içerisine alınan dolgunun (enerji) artması, yanma basıncını ve atalet kuvvetlerini arttırarak $a_{\text {toplam }}$ değerini de arttırmıştır. Benzer eğilim motor gürültüsünde de (Şekil 6) görülmektedir.

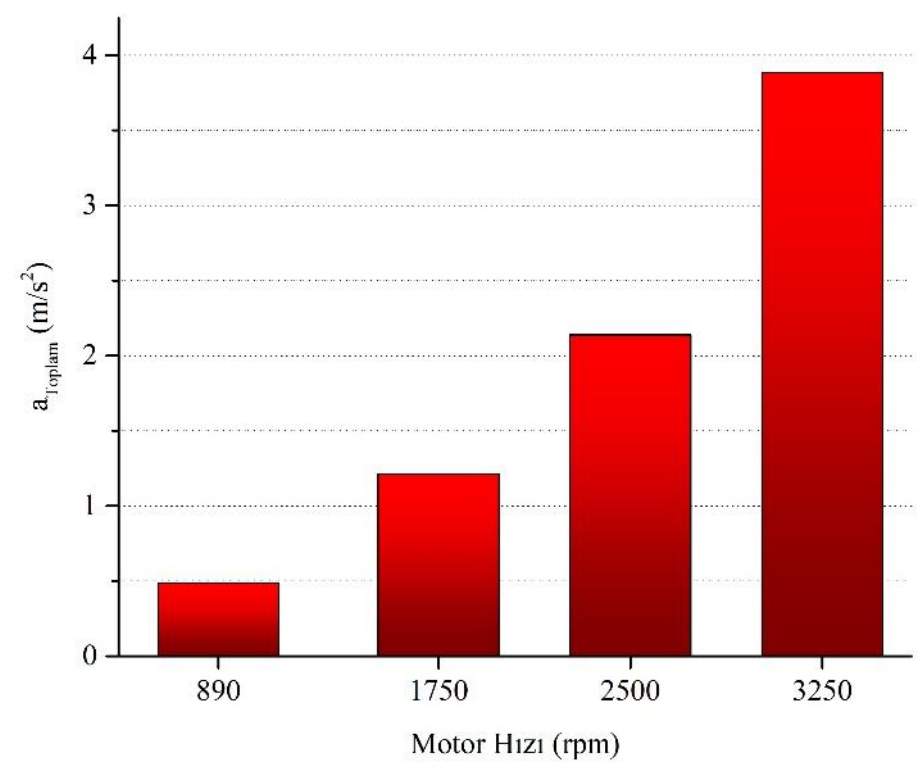

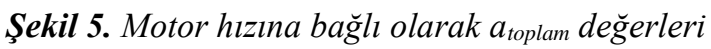




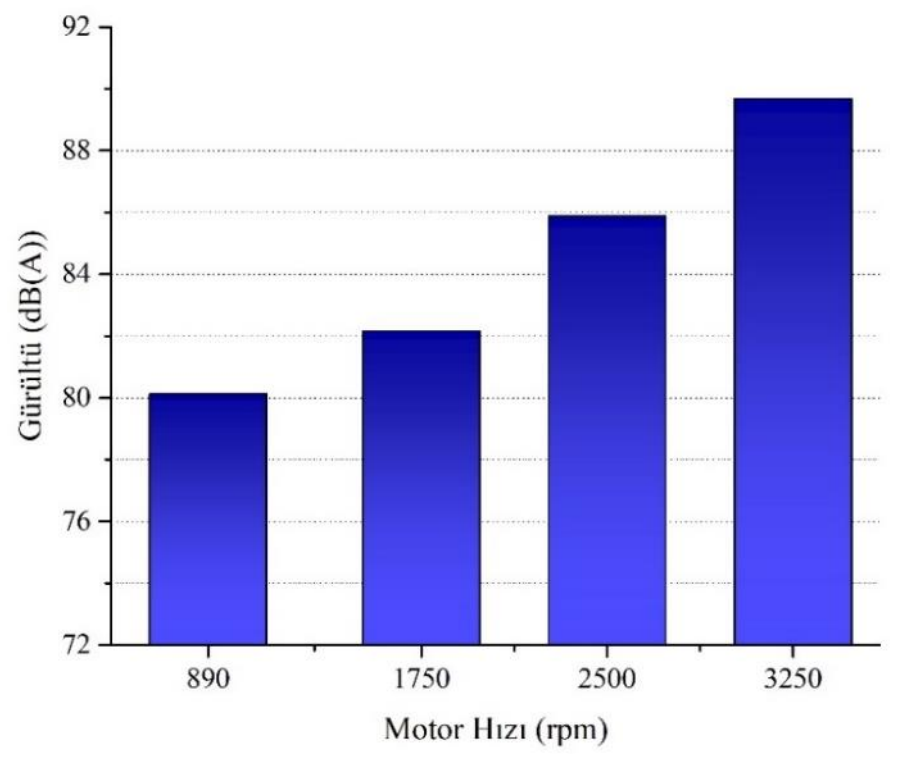

Şekil 6. Motor hızına bağll olarak gürültünün değişimi

Şekil 7 ve 8 'de iki farklı motor devrinde ( 1750 ve $2500 \mathrm{rpm}$ ) ve iki farklı motor yükünde ( 60 ve 80 $\mathrm{Nm}$ ) toplam ortalama titreşim ve gürültünün değişimi görülmektedir. Toplam ortalama titreşim yüksüz olarak gerçekleştirilen deneylerin sonuçlarına benzer bir şekilde motor devrine bağlı olarak artış göstermektedir. Ayrıca motor yükünün artması titreşimde de artışa neden olmaktadır. Motor daha yüksek yük altında çalıştırılmak istendiğinde gaz kelebek açıklığının buna uygun olarak daha fazla açılmasını gerektirmektedir. Silindir içerisine alınan dolgunun (enerjini) artması yanma odasındaki basıncı yükselttiğinden titreşim artış göstermektedir. Titreşim bir sonucu olan gürültü de benzer bir değişim göstermektedir.

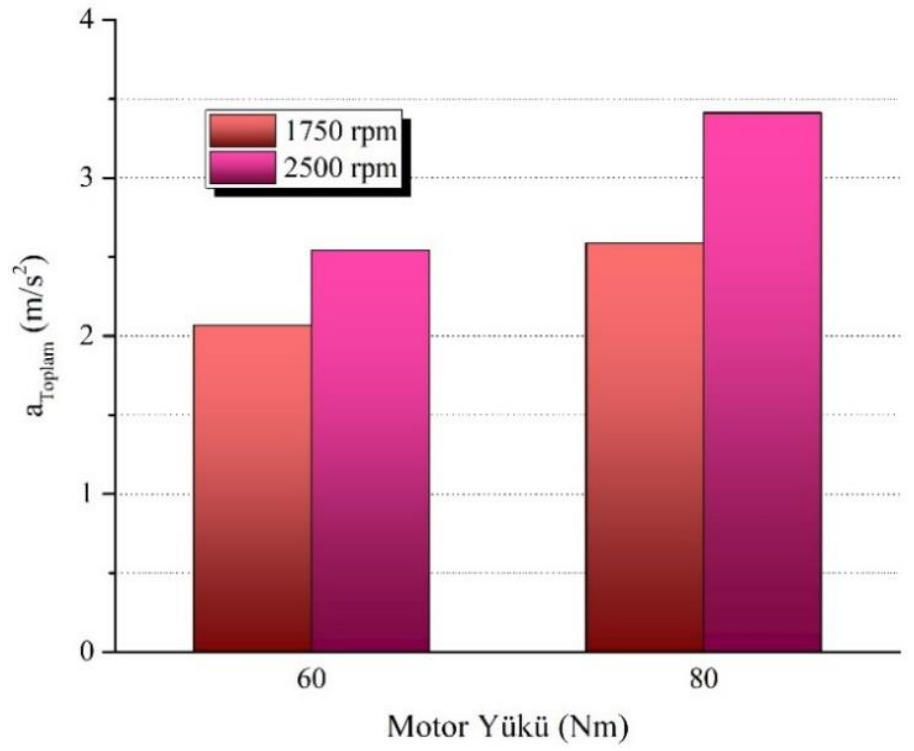

Şekil 7. Motor yüküne bağll olarak $a_{\text {toplam }}$ değerleri 


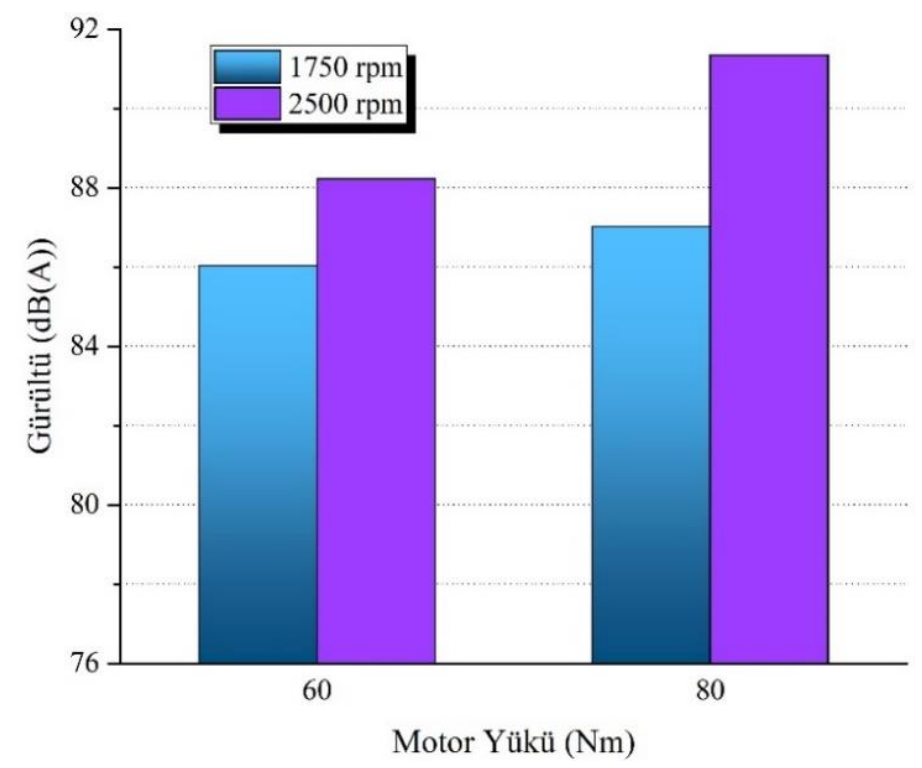

Şekil 8. Farklı motor yüklerinde gürültünün değişimi

\section{IV.SONUC}

Buji ile ateşlemeli bir motorda motor devir ve yüküne bağlı olarak titreşim ve gürültü değişiminin incelendiği bu çalışmada $\mathrm{x}$, $\mathrm{y}$ ve $\mathrm{z}$ eksenlerinden elde edilen verilere göre zaman bölgesi analizi yapılarak, motorun ortalama titreşim değerleri belirlenmiştir. Motor gürültü emisyon değerleri ve titreşim değerlerinin motor devrine ve yüküne bağlı olarak arttığı görülmüştür.

Yüksüz motor deneylerinde toplam ortalama titreşim, motor devrine bağlı olarak artış göstermiştir. $3250 \mathrm{rpm}$ motor devrindeki toplam ortalama titreşim rölanti devrindekinin 8 katı olarak gerçekleşmiştir. Gürültü ise; 9,6 db(A) artmıştır. Yüksüz durumda, tüm devirler için dikey (z) yönde ch3 kanalından en büyük titreşim değerleri elde edilmiştir. Bu sonuçta atalet kuvvetlerinin dikey doğrultuda en büyük olması etkili olmaktadır.

Yük altındaki çalışmada motor titreşim ve gürültüsü motor torkuna göre artmıştır. $1750 \mathrm{rpm}$ motor devrinde $80 \mathrm{Nm}$ yükteki toplam ortalama titreşim, aynı devirdeki yüksüz haldekinin 2,1 katıdır. Gürültü ise; 4,9 db(A) artmıştır. Motor yükünün titreşim ve gürültüye etkisinin incelendiği bir diğer motor devrinde de $(2500 \mathrm{rpm})$ benzer bir değişim elde edilmiştir. $2500 \mathrm{rpm}$ motor devrinde en yüksek yükteki $(80 \mathrm{Nm})$ toplam ortalama titreşim, yüksüz haldekinin 1,6 katı olduğu görülmüştür. Gürültü ise; $5,5 \mathrm{db}(\mathrm{A})$ artmıştır.

Motor titreşimleri ve gürültüsü çevrim sıklığı (motor devri) ve silindir içi basıncından (motor yükü) doğrudan etkilenmektedir. Yanma kaynaklı gürültü, yanma odasındaki yakıtın yanma hızının kontrolü ile düşürülebilir. Motor gürültüsü seviyesi, yanma hızına ve bunun bir sonucu olarak silindir basıncı artış oranına bağlıdır. Motor devrinin artmasıyla artan atalet kuvvetleri ve basınç artış hızı, motorun titreşim ve gürültü seviyesini arttırmıştır.

\section{KAYNAKLAR}

[1] S. Sarıdemir, N. Alçelik ve İ. Uygur, "Biyodizel-Dizel Yakıt Karışımlarının Motor Titreşimine Olan Etkisinin İncelenmesi," Makine Teknolojileri Elektronik Dergisi, c. 13, s. 4, ss. 103-110, 2016. 
[2] N. S. Ahirrao, S. P. Bhosle and D. V. Nehete, "Dynamics and Vibration Measurements in Engines," Procedia Manufacturing, c. 20, ss. 434-439, 2018.

[3] C. Patel, N. Tiwari and A. K. Agarwal, "Experimental Investigations of Soyabean and Rapeseed Svo and Biodiesels on Engine Noise, Vibrations, and Engine Characteristics," Fuel, c. 238, ss. 86-97, 2019.

[4] P. O. A. L. Davies and K. R. Holland, "I.C. Engine Intake and Exhaust Noise Assessment," Journal of Sound and Vibration, c. 223, s. 3, ss. 425-444, 1999.

[5] J. G. Ih and K. S. Peat, "On the Causes of Negative Source Impedance in the Measurement of Intake and Exhaust Noise Sources," Applied Acoustics, c. 63, ss. 153-171, 2002.

[6] N. Gültekin, M. Mayda ve M. Kilit, "Benzin ve Dizel Motorlarda Devir Sayısının Titreşime Olan Etkisinin İncelenmesi,” BEÜ Fen Bilimleri Dergisi, c. 6, s. 2, ss. 39-43, 2017.

[7] S. Sarıdemir, F. Polat ve M. Kılınçel, "Motor Devir ve Yükünün Titreşim ve Gürültü Emisyonuna Olan Etkisinin İncelenmesi," El-Cezeri Fen ve Mühendislik Dergisi, c. 3, s. 3, ss. 459466, 2016.

[8] H. Karabulut, E. Öztürk ve C. Çınar, "Tek Silindirli Dört Zamanlı Bir Dizel Motorunun Dinamik Modeli ve Titreşimlerinin İncelenmesi," Gazi Üniversitesi Mühendislik Mimarlık Fakültesi Dergisi, c. 26, s. 1, ss. 173-183, 2011.

[9] E. Öztürk ve H. Karabulut, "Tek Silindirli Bir Dizel Motorunun Dinamik ve Titreşim Analizleri," Gazi Üniversitesi Mühendislik Mimarlık Fakültesi Dergisi, c. 27, s. 3, ss. 491-500, 2012.

[10] İ. Esen ve İ. Tacir, "Ev Tipi Çamaşır Makinasında Titreşim Analizi,” Düzce Üniversitesi Bilim ve Teknoloji Dergisi, c. 4, s. 2, ss. 443-452, 2016.

[11] M. R. Seifi, S. R. Hassan-Beygi, B. Ghobadian, U. Desideri and M. Antonelli, "Experimental Investigation of a Diesel Engine Power, Torque and Noise Emission Using Water-Diesel Emulsions," Fuel, c. 166, ss. 392-399, 2016.

[12] D. P. Satsangi and N. Tiwari, "Experimental Investigation on Combustion, Noise, Vibrations, Performance and Emissions Characteristics of Diesel/N-Butanol Blends Driven Genset Engine," Fuel, c. 221, ss. 44-60, 2018.

[13] A. Taghizadeh-Alisaraei, B. Ghobadian, T. Tavakoli-Hashjin and S. S. Mohtasebi, "Vibration Analysis of a Diesel Engine Using Biodiesel and Petrodiesel Fuel Blends," Fuel, c. 102, ss. 414-422, 2012.

[14] E. Uludamar, E, Tosun and K. Aydın, "Experimental and Regression Analysis of Noise and Vibration of a Compression Ignition Engine Fuelled with Various Biodiesels," Fuel, c. 177, ss. 326$333,2016$.

[15] S. Saridemir, "The Effect of Dwell Angle on Vibration Characteristics of Camshaft Bearing Housings," Journal of Mechanical Science and Technology, c. 27, s. 12, ss. 3571-3577, 2013.

[16] S. Sarıdemir and H. Saruhan, "Experimental Analysis of Maximum Valve Lift Effects in CamFollower System for Internal Combustion Engines," Journal of Mechanical Science and Technology, c. 28, s. 9, ss. 3443-3448, 2014. 